\title{
Pre-service teachers' cultural and teaching experiences abroad
}

\section{Armağan Ateşkan}

To cite this article: Armağan Ateșkan (2016) Pre-service teachers' cultural and teaching experiences abroad, Journal of Education for Teaching, 42:2, 135-148, DOI: 10.1080/02607476.2016.1144634

To link to this article: https://doi.org/10.1080/02607476.2016.1144634

曲 Published online: 21 Feb 2016.

Submit your article to this journal $\pi$

LII Article views: 427

Q View related articles $₫$

View Crossmark data $\nearrow$

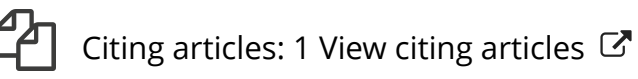




\title{
Pre-service teachers' cultural and teaching experiences abroad
}

\author{
Armağan Ateşkan \\ Graduate School of Education, Bilkent University, Ankara, Turkey
}

\begin{abstract}
This study investigates Turkish pre-service teachers' experiences related to a two-month international teaching and cultural experience in the United States of America. In total, 289 graduate students from Turkey participated in a collaborative project from 2001 to 2010. The experience included an orientation week, six weeks of student teaching in a high school, seminars and projects at lowa State University and cultural visits. The data were collected through a pre-service teacher questionnaire and their reflective journals. The results showed that pre-service teachers perceived the international teaching experience helped them develop professionally and personally. Through crosscultural exchanges with their mentors along with other students and their community, the pre-service teachers expanded their knowledge of a new culture and adapted to a new working environment.
\end{abstract}

\section{ARTICLE HISTORY}

Received 25 November 2015

Accepted 18 January 2016

\section{KEYWORDS}

Pre-service teacher education; cross-cultural experience; international teaching practice; professional development

\section{Introduction}

Teaching abroad and experiencing another culture has a valuable effect on pre-service teachers' professional and personal development (Akşit and Sands 2006; Barkhuizen and Feryok 2006; Cushner and Mahon 2002). For this reason, international teaching experience is recommended and various education programmes offer this opportunity (Baker and GiacchinoBaker 2000; Lupi, Batey, and Turner 2012; Scoffham and Barnes 2009). Pre-service teachers in Turkey do not spend as much time in schools; therefore, to increase pre-service teachers' time in schools, a teacher training programme that included an internship in an American high school was developed at a private non-profit university in Ankara, Turkey in 2000. The programme recruited graduates of biology, mathematics, English, Turkish and history from 20 universities. The programme is taught in English, so pre-service teachers needed a high proficiency in English, especially for teaching their chosen major. Given the complexity of science and mathematics, mastery of English is especially important for students planning to teach those subjects.

Bilkent University is a non-profit university in Turkey, and all graduate education students are awarded a scholarship for full tuition. Because of this policy, the admission process 
does not favour those of higher socio-economic status. The two-year teacher education programme culminates in qualified teacher status, and also it awards a master's degree. During the first year of the programme, pre-service teachers work in five schools. At the beginning, they are in schools one day a week. There they follow activities designed to introduce them to teachers, students, teaching and school life. They also learn how the school's components work together. By the end of the year, pre-service teachers have progressed from observing classes weekly to teaching one or two lessons a day. A block internship of six weeks follows, and by the end of the third semester, students are ready for their international internship. Upon their return, students take two courses for the last semester to finish the programme. As an output, programme graduates have obtained teaching jobs in many of Turkey's well-known and prestigious schools, so far in some 12 cities. Some of the alumni have started their PhD studies in Turkey and abroad.

As a component of this programme, Bilkent University received a grant from the US Department of State for nine years that enabled every student enrolled in the teacher education programme to spend two months teaching in the US. From 2002 to 2005, just the university stated above had this opportunity. Because of the programme's success, however, in 2005, the Fulbright Commission in Ankara and the US Embassy selected pre-service teachers from other Turkish universities to join the group; thus, these students are included in the study.

lowa State University (ISU), in Ames, lowa, was the sister institution awarded the grant in the US; their role was to organise the internship for the Turkish students. In addition to organisational expenses, the grant paid for students' flights and transportation, a daily allowance, visits to Chicago and Washington, DC and textbooks and educational books needed in the US.

Studies have found that professional and personal development of pre-service teachers is an important factor since they will become future teachers (Sutherland, Howard, and Markauskaite 2010) and affect their community (Lukacs 2015). This research aims to explore the pre-service teachers' professional and personal development experiences including in and out of school. This may help to improve current teaching experiences and accordingly improve the teacher education programme.

The main research objective for this study was to gain insights into the pre-service teachers' perceived professional gains and personal development from their experiences within an international context.

\section{Research review and theoretical framework}

Student teaching is an important part of teacher education. For effective teacher training, theory that is learned in education faculties should be practised in schools. In addition to internships in their own countries, some pre-service teachers are privileged to experience international internships. The nature of such programmes and their impact on pre-service teachers' personal and professional development has been explored in research (Cushner 2004; Cushner and Mahon 2002; Lupi, Batey, and Turner 2012; Scoffham and Barnes 2009; Stachowski, Richardson, and Henderson 2003). Cushner (2007) outlines the benefits of these programmes:

In addition to being exposed to new pedagogical approaches and educational philosophies, overseas pre-service teachers gain a significant amount of self-knowledge, develop personal 
confidence and professional competence, as well as a greater understanding of both global and domestic diversity. (30)

Other researchers also note that international teaching allows pre-service teachers to observe and apply new pedagogical approaches and teaching techniques (Grossman, Onkol, and Sands 2007; Grossman and Sands 2008). Sometimes (as can be the case in Turkey) because of the school environment, curriculum and/or a lack of educational materials, pre-service teachers are unable to apply the techniques they have learned in schools in their own country. It is possible to read about or attend seminars regarding teaching and learning methods in other countries, but these approaches do not compare to first-hand experience (Sandgren et al. 1999). Further, teaching native speakers a subject when English is not their first language increases pre-service teachers' self-confidence despite the challenges of vocabulary, grammar and accent (Alberts 2008; Spooner-Lane, Tangen, and Campbell 2009).

Cross (1998) finds that pre-service teachers become more independent when they are in an international setting and are better able to make decisions at their working environment once they return home. Living in a different culture helps students develop global awareness (Jarchow et al. 1996). Wilson (1987) states that 'cross-cultural experience leads to global perspectives necessary for global education to happen in schools' (521). When pre-service teachers live abroad, they are better able to reflect on their own lives and the education system of their own country and make comparisons and judgements (Cushner 2007). In their report of the Overseas Student Teaching Project at Indiana University, Mahan and Stachowski (1994) state that:

By immersing themselves for several weeks in schools, homes and communities where things are done differently, pre-service teachers inevitably experience personal and professional changes usually leading to insights that might never have surfaced, learning that no book can supply, and a professional self-portrait that in-state experiences alone cannot reveal. Pre-service teachers also gain a broader perspective on the world. (29-30)

Kabilan (2013) formed a framework about benefits of the international teaching practice for the pre-service teachers' professional and personal development as given in Figure 1.

The research outlined in this paper explores the experiences of Turkish pre-service teachers in the US participating in a collaborative project between a private nonprofit university and ISU. Based on the research literature, no other studies explore Turkish pre-service teachers' thoughts about and experiences of internship abroad. Furthermore, this study took place over nine years, further ensuring the applicability of its results.

\section{Methods}

This study aimed to develop an understanding of Turkish pre-service teachers' international teaching experiences by examining data from a longitudinal sizable case study of cohorts of students over an eight year period who received a two-month internship programme in and around Ames, lowa.

\section{Context of the study and programme details}

ISU collaborated with Bilkent University and arranged the following activities for the Turkish pre-service teachers in the US: a ten-day orientation programme, which included 


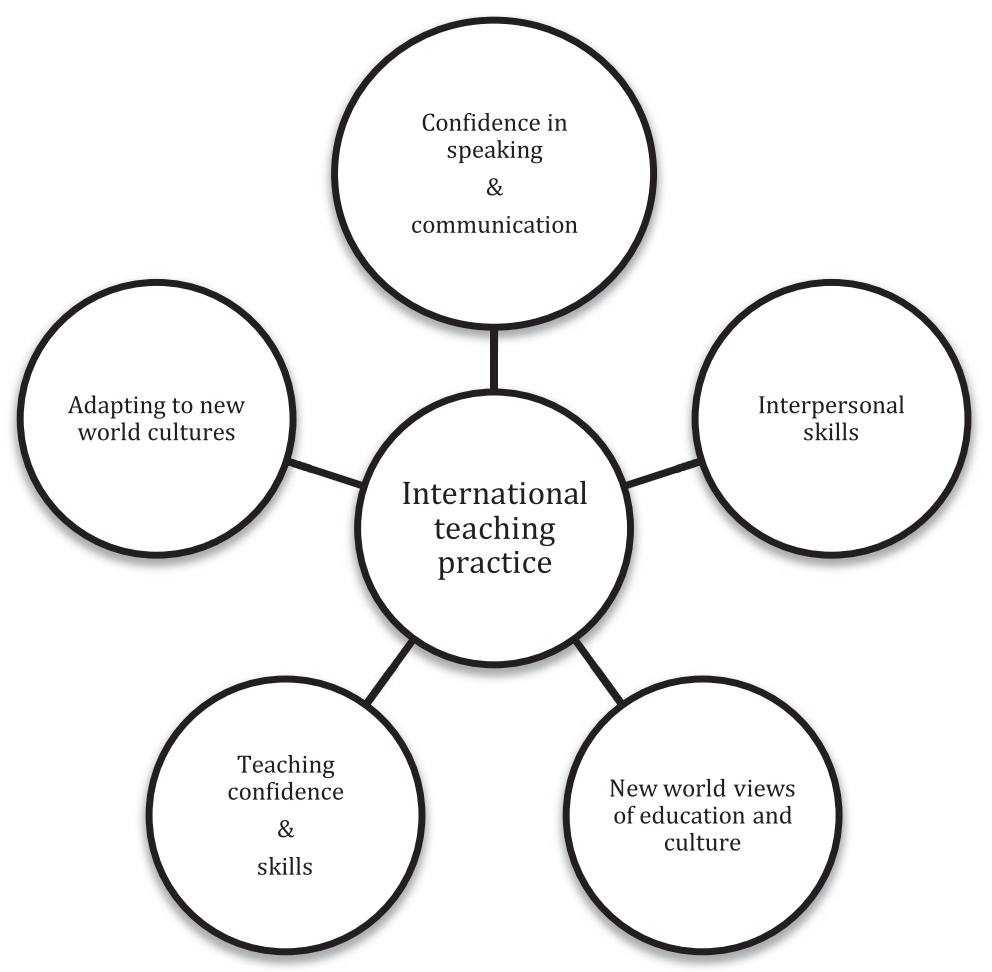

Figure 1. Framework for benefits of international teaching practice (Kabilan 2013, 202).

private school and public school visits in and around Ames, lowa; a six-week internship in a school; seminars at the university; a long weekend in Chicago (including a school visit) and, planned by the State Department, four days in Washington at the end of the US stay. Prior to the start of the US aspect of the programme, ISU organisers came to Turkey each year to meet and interview the pre-service teachers and review their CVs. The organisers used this experience to best match pre-service teachers with a mentor in the US.

The orientation began with a group welcome to the university and familiarised students with their accommodations. Throughout the programme, pre-service teachers stayed on campus in ISU graduate-student housing and cooked their own food. (For additional cultural exchange, students also stayed one weekend with an American family.) After settling in, the pre-service teachers toured the campus and the area and attended a day of lessons at the schools in which they would be working. ISU, which places their own pre-service teachers in the same area schools, determined which schools the Turkish pre-service teachers would intern at and who their mentor teacher would be. During the six-week internship, the pre-service teachers worked in pairs. This arrangement provided students support in their new environment and helped them learn about working collaboratively. They also spent one afternoon per week in seminars at ISU organised specifically for them and related to technology and other relevant subjects. 


\section{Data collection methods and instruments}

The data were collected from 2001 to 2010. To gather the data, an open-ended questionnaire and the pre-service teachers' reflective journals were used. The open-ended questionnaire was designed and administered to the Turkish pre-service teachers as soon as they returned from the US and collected one week later. The questionnaire was developed over the eight years as follows: In the first two years of the research, there were 19 questions on the questionnaire. In the following three years, there were 24 questions and in the last three years there were 27 questions. The questionnaire was modified based on suggestions from the researchers and feedback from the respondents, and included rating questions, open-ended questions and yes/no questions. The questions were grouped in sections related to:

- School: learning/teaching strategies, learning technologies, students, school community, cultural exchanges, mentor information and days they spent with the pre-service teachers, lessons taught, extra-curricular activities, visitors from ISU,

- home stays,

- campus accommodation,

- monetary allowance,

- cross-cultural understandings,

- campus seminars.

Pre-service teacher reflective journals were collected as soon as they returned from US. Journals included lesson observation forms, lesson plans with materials, mentor meeting and feedback forms, self-evaluation forms, weekly reports, cultural and curriculum projects.

\section{Data analysis}

A mixed data approach was used to analyse both qualitative and quantitative data. Quantitative data were analysed using descriptive statistics to present percentages. Qualitative data were analysed using free software called Weft QDA. All data were converted to MS Word, and saved as notepad for transfer of data to Weft QDA. The framework of questionnaire questions was used to develop a coding scheme (Strauss and Corbin 1990). Tags and labels were given to the themes included in this 'provisional start list' (Miles and Huberman 1994). These themes and their codes were then transformed into sub-codes for more differentiation. These themes were formed in Weft QDA software and transferred notepad texts were marked. Later, the data were transferred as an html document. For triangulation and enrichment of the research, pre-service teachers' reflective journals were analysed and the coding scheme was revisited and revised to add more detail.

\section{Participants}

Of the 289 pre-service teachers involved in the project from 2001 to 2010, 251 participated in the research and all of those returned the questionnaire and reflective journals. The 38 pre-service teachers enrolled in the last year the programme operated did not take part in this study, because they did not fill in the questionnaire or submit their journals. Of the respondents, $80 \%$ were female and $20 \%$ were male. The pre-service teachers were pursuing 
a master programme and had earned their undergraduate degree from 20 universities across Turkey.

\section{Results}

This section includes information about the participants' demographic data. The theoretical framework is used to classify five main categories of benefits of international teaching practice on their professional and personal development.

\section{Demographics}

For the first three years of the programme (2001-2003), pre-service teachers travelled to the United States in September of their second year. Beginning in the fourth year (the 2004-2005 school year), they went in January; this makes it appear that the 2004 cohort is missing but they are included in the 2005 data. In 2006, the number of pre-service teachers increased because students from other universities participated. In 2010, 38 pre-service teachers attended the programme, but they did not take part in the research, thus are not included in Table 1.

The pre-service teachers were placed in high schools in Ames, Des Moines and other towns in the region. At school, pre-service teachers observed and then taught lessons, took part in after-school activities and attended various meetings. They taught between 9 and 39 lessons during their six-week internship. The average number of lessons taught was 30.1.

\section{Pre-service teachers' confidence in speaking and communication}

Pre-service teachers stated that they are more confident in speaking and teaching in English compared to their skills before they did their international teaching practicum. It was an advantage for them to teach their subject area to native speakers in an international context. Pre-service teachers highlighted how appreciative the American students were during that period since they were teaching the subject at second language. Pre-service teacher (PT) 1 stated:

I was very nervous at the beginning of the internship. I had hard time to concentrate on student questions and their answers because of not feeling confident with the language. Through the middle of the experience, I became more confident with the help of my mentor's comments and students' tolerance.

The mentor feedback reports in pre-service teachers' reflective journals also showed that they improved their confidence in speaking and communication with students almost at the third week of the experience.

Table 1. Number of participants from 2001 to 2010.

\begin{tabular}{lccccccccc}
\hline Year & 2001 & 2002 & 2003 & 2005 & 2006 & 2007 & 2008 & 2009 & Total \\
\hline Number of participants & 23 & 26 & 26 & 26 & 35 & 38 & 38 & 39 & 251 \\
\hline
\end{tabular}




\section{Pre-service teachers' teaching confidence and skills}

Pre-service teachers reported that teaching practice abroad helped them to increase their confidence and improved their teaching skills. Pre-service teachers worked with mentor teachers, who were mainly responsible for Turkish pre-service teachers when they were at the schools. They observed and taught their mentor's classes, and sometimes in the classes of other teachers. The pre-service teachers became familiar with several learning strategies and approaches. According to their responses, student-centred teaching was the most observed learning approach in the US schools visited. Among such learning strategies, the most common technique was collaborative/cooperative learning (94.5\%). The second was anchored instruction (72.7\%); the third was authentic learning (67.2\%); and problem-based learning was the last (58.0\%).

Examples of student-centred learning strategies included: a microscope that could be connected to a screen; reading assignments based on novels as a part of the curriculum; using a SMART Board, graphing calculators and the Geometer's Sketchpad and conducting long-term experiments in science classrooms. PT 2 stated:

[While] setting up a biosphere, the students were not asked to do everything by following a ready procedure. Instead, my mentor asked them some critical questions to make them think. While the students were trying to find the answers, they also found the materials [needed to create the] biosphere.

In addition to observing new teaching techniques and approaches, the pre-service teachers stated that in the American schools, they could practise what they had learned in theory at their home universities. Such practice is not always possible in Turkey due to restrictions of curriculum and/or lack of resources. PT 3 said:

We don't have green houses at schools in Turkey. Some of the environmental studies that need green houses are not possible to conduct. I had a chance to apply the teaching techniques that I learned in theory. This facilitates my self-confidence about teaching skills.

\section{Pre-service teachers' interpersonal skills}

The pre-service teachers stated that they improved their interpersonal skills throughout international teaching practice. In the schools, pre-service teachers interacted daily with teachers, students and staff. They gave presentations about Turkey to teachers and students. At the end of the presentations, the US teachers and students generally stated that they were curious about and wanted to visit Turkey and some of the mentors did visit their pre-service teachers later. They were surprised by questions that the students asked. For example, PT 4 stated, 'The students asked about the clothes that we wear in Turkey. They thought that we wore different clothes in Turkey than [we did in the] US'.

Turkish pre-service teachers also improved their interpersonal skills beyond the classroom. Most (84.7\%) observed and interacted with the principal of the school, $61.9 \%$ received in-service training and just over half (55\%) attended departmental meetings. One quarter (25.9\%) were present at parent-teacher conferences and 38.6\% met parents in other settings. Preservice teachers also attended science conventions, staff development sessions and health conferences. They participated in various clubs and sports activities in the US. Clubs such as Yearbook, Debating, Philosophy, Theatre, Computing and Newspaper welcomed them. American football, volleyball, soccer, cross-country, basketball, swimming, skiing, wrestling, 
Table 2. Activities that pre-service teachers and home-stay families did together.

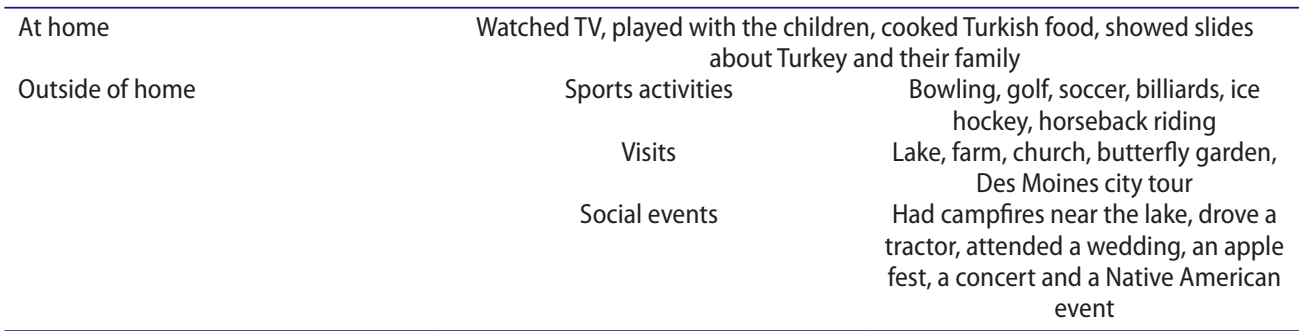

bowling and badminton were some of the sports they got involved in. They stated that these activities helped them to appreciate what they can do and how easy it was to communicate with people from different cultures. Besides working in schools, pre-service teachers interacted with instructors, students and staff through projects and seminars and during the Turkish celebration they organised on campus.

Outside of educational activities, all pre-service teachers stayed with at least one family for two days to experience life in an American home. For some of the pre-service teachers, it was the first time that they stayed outside their home and interacted with different families. The activities that they did with their host families are summarised in Table 2.

\section{Pre-service teachers' new world views of education and culture}

Pre-service teachers stated that international teaching practice developed their world views related to school including school climate, resources that schools have, and culture including involvement in various community activities and visits to other cities. Pre-service teacher 4 stated that she had a chance to compare two world views of education and realised the differences, benefits and challenges.

Pre-service teachers reported that every teacher in the US had their own classroom with resources. In most Turkish schools, a class of students has their own room and teachers move from one location to another, which makes it difficult to have permanent resources in the classrooms. In the US, teachers receive books, CDs and exam preparation tools from the publishing companies. In Turkey, teachers receive teacher editions of textbooks, which include the answers to the questions asked in the students' textbooks, but have few additional teaching resources. For example, pre-service teachers performed whole animal dissections in the US schools; Turkish public schools do not have such resources, whereas some Turkish private schools have. In US schools, student textbooks belong to the school and are returned at the end of each year. In Turkey, students receive textbooks from the government free of charge and do not need to return them. All the observed US schools had greenhouses, fully equipped science laboratories and computer labs. They also had laptop computers with hubs that could be booked in advance and moved from classroom to classroom. These materials expanded students' learning opportunities and facilitated access to learning technologies; the latter of which respondents stated were widely used in US classrooms. The Internet was the most used technology in the classroom (85.3\%), multimedia tools such as computers, office programmes, projectors and cameras ranked second (82.8\%), video-based technologies were third (79.4\%) and online forums ranked fourth (23.1\%). For the first five years of 
Table 3. Pre-service teachers' involvement with the community.

\begin{tabular}{lc} 
Visits & $\begin{array}{r}\text { Home stays, visits to mentor's or other teachers' houses, a } \\
\text { farm, schools, museums and conferences } \\
\text { Sports activities participated in } \\
\text { Cultural events } \\
\begin{array}{l}\text { Celebrations and ceremonies } \\
\text { Theatres, concerts and school productions }\end{array} \\
\text { Attending church services, observing Homecoming } \\
\text { Week, celebrating Halloween and Martin Luther King Day, } \\
\text { attending a baby shower }\end{array}$ \\
\hline
\end{tabular}

the internship programme, learning technologies were not common in Turkey. Their use is now growing, especially in schools where alumni of the programme are working.

Besides these positive experiences and observations, they reported that there are some challenges related to schooling which are not very common to come across in Turkey, in particular the security at school. Pre-service teachers stated that there was a police car in front of some of the schools for security. PT 5 stated, 'I [was] shocked when I saw a metal detector at the school gate. I heard that sometimes students bring guns to the school'.

Almost all (92\%) of the pre-service teachers stated that they became involved with community activities to learn about new culture (see Table 3 ).

All students except one (99.6\%) said that they were able to contribute to the community's understanding of Turkish culture, history and tradition. (The one student felt that she didn't have enough interaction in the community outside of school.) Some students gave presentations about Turkey at their schools and others participated in cultural projects with American university students or gave newspaper interviews. Students also shared information about Turkey with their home-stay families and through day-to-day interactions in and around the community. As a group, the Turkish students hosted a Turkish day at ISU. During these cultural activities, pre-service teachers had a chance to work with multicultural group of people that were professional and supportive.

Pre-service teachers visited Chicago and Washington, DC as a part of their internship project. These cities showed students a side of the US which was different from what they had experienced in the smaller communities of lowa. PT 6 said, 'When we arrived in Chicago, I had a feeling that now I am in [the] America that I watched in the movies'. Students thought museums and government buildings to be particularly impressive. PT 7 stated, 'I [was] amazed with the museums and monuments [in] Washington, DC Additionally, most of them are free of charge'.

\section{Pre-service teachers' adapting to new working cultures}

The pre-service teachers experienced different working cultures compared to their home country including schools, students and teaching/learning approaches. Throughout their practice, they learned to adapt to these new settings.

They were surprised to see the differences between urban and rural schools. They observed that in urban schools students were from a variety of cultures and less respectful to their teachers and each other compared to students in rural schools. In Turkey, private schools have better standards and equipment; however, students found the opposite to be true in the US.

According to the pre-service teachers, there were some similarities between Turkish and American students. For example, students in both countries are ready to be noisy when the 
opportunity arises, mostly by talking without raising their hands. Many Turkish and American students find mathematics difficult. Both groups like visually based learning, experiments and other hands-on activities. Like some Turkish students, American students were seen as creative and had a sense of humour. On the other hand, they did observe some differences between students of the two countries. Many of the pre-service teachers in the study (70\%) felt that Turkish students were more enthusiastic and interested in school than American students. The US students seemed to prefer writing to speaking, whereas Turkish students prefer speaking and participate more in class discussions. PT 8 stated that the American students were' $[\mathrm{m}]$ ore mature than Turkish students, respectful, polite and welcoming, quiet, perhaps too quiet, as it was difficult to get them to participate in a discussion or answer or ask questions'. PT 9 wrote:

'American students did not intend to answer my questions. They were so silent. If you want them to answer the question you need to try hard. First I felt that they didn't like me, but then

I understood that they act like that in every lesson'.

and PT 10 stated, 'Classroom management was easy. They are good at taking notes, and [doing practical lab] work'.

American students were perceived as more responsible and respectful, knowing their responsibilities and accepting the consequences of their actions. However, students wondered if students in Ames-area schools were more socialised into appropriate school behaviour compared to other American students. PT 11 stated:

'We visited a school in Washington DC as a day trip. We six biology pre-service teachers observed a chemistry classroom. Students in the classroom started to whistle when they saw us. The teacher [chose not to discipline them]. I felt very uncomfortable and felt lucky that we did our internship [in] lowa'.

American students seem to be more involved in activities such as concerts, sports and theatre activities at school than Turkish students. After-school activities facilitated by schools are common in US schools compared to the majority of Turkish schools. American students in Ames are seen as hardworking and diligent.

Most American students had part-time or volunteer jobs, whereas in Turkey, the majority of high schools students are not employed. According to the data, students felt that some of the US teachers treated the American students like adults, which is not the case with students and teachers in Turkey. Because of greater access to technology, US students were more used to it and more open to new ideas than Turkish students. If US students do not have computers at home, they use them at school, whereas in Turkey it is not easy to find computers for each student.

Pre-service teachers adapted to the new working culture that is giving an importance to the education of each and every child. Thus, PT 12 stated:

One morning I came to school. There was a medium-sized yellow school bus waiting in front of the school gate. Suddenly the lift started to work and a student appeared who was using a wheelchair. The student was breathing using an oxygen tube placed at the back of the wheelchair. I am very much impressed that that child is able to come out of home and go to school.

\section{Discussion and conclusions}

Some of the perceived gains that formed the framework of the study could have been achieved through a teaching practice in the pre-service teachers' home country; however, 
there were unique opportunities provided by this international experience that benefited students. They learned to adapt to a new culture and to appreciate different worldviews of people. Most important for their professional development was the fact that they were challenged to teach their subject to native speakers in English.

It was a privilege for Turkish pre-service teachers to live and teach in another country. They were often surprised and impressed by their experiences, and sometimes they struggled and then overcome these problems. The pre-service teachers learned about a new culture and shared their own way of life with their host country. Consistent with other research done in this area (Black and Duhon 2006; Cushner 2007; Lupi, Batey, and Turner 2012; Scoffham and Barnes 2009; Thomas 2006), the results of this research show that an international teaching experience helps pre-service teachers develop their professional and personal skills and increase their global awareness.

As the Turkish pre-service teachers' confidence about speaking and communication in the host country's language and international teaching experience improved, they became more aware of their self-confidence to teach a subject in a different language (English). One reason for this positive outcome was the sufficient amount of teaching practices that they gained in the US classrooms that were monitored by their mentors. Kabilan (2013) also found that Malaysian pre-service teachers had more time to use English during teaching practice in the Maldives which helped them to improve their speaking and communication skills. Besides teaching their subject area in English, Turkish pre-service teachers communicated with school staff and other community members in English for their daily conversation. They attended extra-curricular activities at school that facilitated use of their communication skills.

Pre-service teachers improved their teaching confidence and skills during their internship. Work at schools that develops teaching confidence and skills starts with observation of teacher, students and lessons (Clark 1996). In this programme, pre-service teachers had a chance to observe student-centred teaching approaches and collaborative/cooperative learning strategies while observing their mentor teachers. Later, they were able to teach lessons that were observed by their mentors. One important issue for improving their teaching confidence was an opportunity to practise in the US what they learned in theory in Turkey, especially practical work. The exam-driven national curriculum and lack of resources in Turkey limit the ability of teachers to provide hands-on experiences for students. These limitations restrict the teaching techniques that are used resulting in a mainly didactic teacher-centred approach being practised at schools in Turkey (Ateşkan et al. 2015).

For most of the programme participants, this experience was their first time out of Turkey. They were far from their families and forced to rely on their own decision-making abilities. They shared housing on the ISU campus and worked in pairs at the schools. Similar to Evans, Alano, and Wong's (2001) findings, students reported that this arrangement helped them get used to living and working with others cooperatively. Also, in Scoffham and Barnes (2009) study, UK pre-service teachers in India stated the impacts of being in a group outside of the home country helped them to be more tolerant and thoughtful towards each other.

Pre-service teachers interacted with many people during their internship such as their mentors, other teachers, administrators and support staff. They interacted with students and answered questions about culture and daily life in Turkey. Some of them were surprised that they had to explain and exchange the information related to their country. They reported that this helped US students to learn about a new culture, especially as most of them had never been out of their state. 
Being part of an American school for six weeks allowed pre-service teachers to compare and contrast different education systems (Clement and Outlaw 2002), including schools, students, teachers, classrooms, resources and teaching/learning strategies. Turkish pre-service teachers think that it is admirable for a teacher to have their own large classroom in the US where they may have all of their teaching resources in their class and so have no need to move from one classroom to another. However, it would seem that American pre-service teachers are not satisfied with the classrooms in the US and they prefer the classrooms in UK that have bigger spaces and tables provided for students (Lupi, Batey, and Turner 2012).

All teaching resources, including lesson plans, worksheets, quizzes and exams, are provided with textbooks in the US which Turkish students like. They believe that having reliable ready-to-use materials saves time and energy. Lupi, Batey, and Turner (2012) found this was not the case in their study done with US pre-service teachers who had an internship in the UK. Participants stated that there was no prescribed textbook for teachers to follow and no support materials. Although at the beginning they found it was hard for them to adjust, later they realised that this lack of ready-made resources improves teachers' creativity.

According to the pre-service teachers in the current study, American students are creative, have a sense of humour and are more responsible and respectful compared to Turkish students. American students are willing to take responsibility since most of them have parttime jobs. On the other hand, Lupi, Batey, and Turner (2012) reported that the US pre-service teachers in their study thought British students were more respectful and responsible than American students.

Regarding school environment and emotional learning, Turkish pre-service teachers observed special education students in schools and appreciated the value given to each child. This emotional experience helped pre-service teachers to question special education in Turkey and to consider the possibilities that could be adopted in their own country. In their study, Scoffham and Barnes (2009) showed that pre-service teachers coming from a system that has a well-established special education programme were distressed when they went to India during their intercultural study visit. Students in this study were not satisfied with the special education programme. A positive outcome of their dismay is that it motivated them to take action to improve the special education programme in their host country.

The importance of home stays in an international teaching experience is widely recognised (Bodycott and Crew 2001; Chaseling 2001). In this programme, all pre-service teachers were invited by an American family for a home stay of two days. The pre-service teachers and families exchanged information and views and the questionnaire results showed that students returned to Turkey with a deeper understanding of a different culture. American families were very welcoming and friendly. Likewise, in Scoffham and Barnes (2009) study, British pre-service teachers found Indian people welcoming and inspiring with their cheerfulness and interest. According to Rogers and Tough (1996) these positive experiences facilitate emotional development of pre-service teachers.

In conclusion, teaching in an international context helps pre-service teachers develop their twenty-first-century skills. As noted by P21 (2016), these include 'world languages, communication skills, global awareness, collaboration, flexibility/adaptability, social and cross-cultural skills, leadership and responsibilities'.

This study has some limitations, such as its unique nature and the questionnaire changing every two to three years. Nevertheless, the results obtained are similar to those of other international internships and prove the value of such exchanges for all parties involved. 
Students, teachers, education institutions and countries would benefit from developing and supporting more such programmes. The data gathered in this research could help design international internship programmes for other universities. It is clear that such experiences are costly and may not be possible for every institution. For universities that cannot afford such experiences, pre-service teacher education programmes may have activities comparable to some of these perceived gains given above. For example, they could invite visitors from overseas and/or visiting international schools during local teaching practice. Another possible solution is that with the recent developments in technology, web-based relationships could be built with foreign schools where pre-service teachers communicate with teachers, students and other school staff through social media. Pre-service teachers may learn about different cultures and the lives of people in other countries by having e-pals with whom they share experiences, worldviews and cultural matters.

As a further study, feedback from mentors, school students and programme supervisors could be analysed and compared other studies to identify similarities, differences and ways to improve internship programmes abroad. A longitudinal study to discover the effects of the internship after the students had been teaching for five to 10 years would be valuable.

\section{Disclosure statement}

No potential conflict of interest was reported by the author.

\section{References}

Akşit, N., and M. K. Sands. 2006. "Turkey: Paradigm Change in Education."In Crosscurrents and Crosscutting Themes: A Volume in Research on Education in Africa, the Caribbean and the Middle East, edited by $\mathrm{K}$. Mutua and C. S. Sunal, 253-271. Greenwich, CT: Information Age Publishing.

Alberts, H. C. 2008. "The Challenges and Opportunities of Foreign-Born Instructors in the Classroom." Journal of Geography in Higher Education 32 (2): 189-203.

Ateşkan, A., J. Onur, S. Sagun, M. Sands, and M. S. Çorlu. 2015. Alignment between the DP and MoNEP in Turkey and the Effects of These Programmemes on the Achievement and Development of University Students. Bethesda, MD: International Baccalaureate Organization.

Baker, F. J., and R. Giacchino-Baker. 2000. Building an International Student Teaching Programme: A California/Mexico Experience. Retrieved from ERIC (ED449143).

Barkhuizen, G., and A. Feryok. 2006. "Pre-Service Teachers' Perceptions of a Short-Term International Experience Programme." Asia-Pacific Journal of Teacher Education 34 (1): 115-134.

Black, H. Tyrone, and D. Duhon. 2006. "Assessing the Impact of Business Study Abroad Programs on Cultural Awareness and Personal Development." Journal of Education for Business 81 (3): 140-144.

Bodycott, P., and V. Crew. 2001. "Short Term English Language Immersion Paradox; Culture Shock; Participant Adjustment." In Language and Cultural Immersion, edited by P. Bodycott and V. Crew, 1-9. Hong Kong: The Hong Kong Institute of Education.

Chaseling, M. 2001. "Home Stay - A Home Away from Home." In Language and Cultural Immersion, edited by P. Bodycott and V. Crew, 113-121. Hong Kong: The Hong Kong Institute of Education.

Clark, D. 1996. "The Changing National Context of Fieldwork in Geography." Journal of Geography in Higher Education 20 (3): 385-391.

Clement, M. C., and M. E. Outlaw. 2002. "Student Teaching Abroad: Learning about Teaching, Culture, and Self." Kappa Delta Pi Record 38 (4): 180-183.

Cross, M. C. 1998. "Self-Efficacy and Cultural Awareness: A Study of Returned Peace Corps Teachers." Paper Presented at the Annual Meeting of the American Educational Research Association, San Diego, CA. Retrieved from ERIC (ED429 976). 
Cushner, K. 2004. Beyond Tourism: A Practical Guide to Meaningful Educational Travel. Lanham, MD: Rowman and Littlefield/Scarecrow Education.

Cushner, K. 2007. "The Role of Experience in the Making of Internationally Minded Teachers." Teacher Education Quarterly 34 (1): 27-39.

Cushner, K., and J. Mahon. 2002. "Overseas Student Teaching: Affecting Personal, Professional, and Global Competencies in an Age of Globalization." Journal of Studies in International Education 6: 44-58.

Evans, M., C. Alano, and J. Wong. 2001. “Does a Short Language Course in an Immersion Setting Help Teachers to Gain in Communicative Competence?" In Language and Cultural Immersion, edited by P. Bodycott and V. Crew, 91-100. Hong Kong: The Hong Kong Institute of Education.

Grossman, G. M., P. E. Onkol, and M. K. Sands. 2007. “Curriculum Reform in Turkish Teacher Education: Attitudes of Teacher Educators towards Change in an EU Candidate Nation." International Journal of Educational Development 27 (2): 138-150.

Grossman, G. M., and M. K. Sands. 2008. "Restructuring Reforms in Turkish Teacher Education: Modernisation and Development in a Dynamic Environment." International Journal of Educational Development 28 (1): 70-80.

Jarchow, E., J.W. McKay, R. R. Powell, and L. F. Quinn. 1996. “Communicating Personal Constructs about Diverse Cultures: A Cross Case Analysis of International Student Teaching." In Teacher Education Yearbook IV: Field Experiences, edited by D. J. McIntyre and D. M. Byrd, 178-196. Sage: Corwin Press.

Kabilan, M. K. 2013. “A Phenomenological Study of an International Teaching Practicum: Pre-Service Teachers' Experiences of Professional Development." Teaching and Teacher Education 36: 198-209.

Lukacs, K. 2015. "For Me, Change is Not a Choice: The Lived Experience of a Teacher Change Agent." American Secondary Education 44 (1): 38-49.

Lupi, M. H., J. J. Batey, and K. Turner. 2012. "Crossing Cultures: US Student Teacher Observations of Pedagogy, Learning, and Practice in Plymouth, UK Schools." Journal of Education for Teaching 38 (4): 483-496.

Mahan, J. M., and L. L. Stachowski. 1994. "The Many Values of International Teaching and Study Experiences for Teacher Education Majors." In Promoting Global Teacher Education: Seven Reports, edited by J. L. Easterly, 15-24. Reston, VA: Association of Teacher Education.

Miles, M. B., and A. M. Huberman. 1994. Qualitative Data Analysis. Thousand Oaks, CA: Sage.

P21-Partnership for 21st Century Learning. 2016. Framework for 21st Century Learning. Accessed January, 2016. http://www.p21.org/about-us/p21-framework

Rogers, M., and A. Tough. 1996. "Facing the Future is Not for Wimps." Futures 28 (5): 491-496.

Sandgren, D., N. Elig, P. Hovde, M. Krejci, and M. Rice. 1999. "How International Experience Affects Teaching: Understanding the Impact of Faculty Study Abroad." Journal of Studies in International Education 3 (1): 33-56.

Scoffham, S., and J. Barnes. 2009. "Transformational Experiences and Deep Learning: The Impact of an Intercultural Study Visit to India on UK Initial Teacher Education Students." Journal of Education for Teaching 35 (3): 257-270.

Spooner-Lane, R., D. Tangen, and M. Campbell. 2009. “The Complexities of Supporting Asian International Pre-Service Teachers as They Undertake Practicum." Asia-Pacific Journal of Teacher Education 37 (1): 79-94.

Stachowski, L., Jayson W. Richardson, and M. Henderson. 2003. "Student Teachers Report on the Influence of Cultural Values on Classroom Practice and Community Involvement: Perspectives from the Navajo Reservation and from Abroad." The Teacher Educator 39 (1): 52-63.

Strauss, A., and J. Corbin. 1990. Basics of Qualitative Research: Grounded Theory Procedures and Techniques. Sage.

Sutherland, L., S. Howard, and L. Markauskaite. 2010. “Professional Identity Creation: Examining the Development of Beginning Pre-Service Teachers'Understanding of Their Work as Teachers." Teaching and Teacher Education 26 (3): 455-465.

Thomas, P. G. 2006. "Pre-Service Practicum Teaching in Central Asia: A Positive Experience for Both Worlds." Journal of Social Studies Research 30 (1): 21-25.

Wilson, A. H. 1987. "Cross-Cultural Experiential Learning for Teachers." Theory into Practice 26: 519-527. 